\title{
Effect of Nafamostat on $N$-Methyl-D-aspartate-Induced Retinal Neuronal and Capillary Degeneration in Rats
}

\author{
Yo Tsuda, Tsutomu Nakahara,* Kaori Ueda, Asami Mori, Kenji Sakamoto, and Kunio Ishii \\ Department of Molecular Pharmacology, Kitasato University School of Pharmaceutical Sciences; 5-9-1 Shirokane, \\ Minato-ku, Tokyo 108-8641, Japan. Received July 22, 2012; accepted September 14, 2012
}

We examined the effects of the serine protease inhibitor nafamostat mesilate on neuronal and vascular injury in rat retinas treated with $N$-methyl-D-aspartate (NMDA). The degree of neuronal degeneration was assessed by measuring the number of cells in the ganglion cell layer and the thickness of the inner plexiform layer. The degree of capillary degeneration was assessed by measuring the number of empty basement membrane sleeves that were left as remnants of the vessels. Significant neuronal and capillary degeneration was observed $7 \mathrm{~d}$ after a single intravitreal injection of NMDA into the eye. Both forms of degeneration were significantly prevented by simultaneous injection of nafamostat mesilate with NMDA. These results indicate that nafamostat mesilate affords protection against the neuro/vascular injury seen in NMDA-treated retinas. Nafamostat mesilate may be considered as a candidate for neuro/vascular protective interventions in retinal diseases associated with glutamate-induced excitotoxicity, such as glaucoma and diabetic retinopathy.

Key words endothelial cell; excitotoxicity; retinal blood vessel; retinal degeneration

Neuronal injury and death play a critical role in the pathogenesis of retinal diseases such as diabetic retinopathy and glaucoma. Glutamate-induced excitotoxicity appears to play an important role in these retinal diseases. ${ }^{1-3)}$ Mechanisms of glutamate-induced neuronal injury or death involve excessive $\mathrm{N}$-methyl-D-aspartate (NMDA) receptor stimulation, leading to excessive $\mathrm{Ca}^{2+}$ influx and subsequent activation of $\mathrm{Ca}^{2+}$. dependent responses, such as formation of nitric oxide (NO) via neuronal NO synthase ${ }^{4,5)}$ and activation of $\mathrm{Ca}^{2+}$-activated proteolytic enzymes, including calpains. ${ }^{6,7)}$ In addition, upregulation of pro-inflammatory cytokines and inflammatory adhesion molecules, ${ }^{8,9}$ increase in matrix metalloproteinase (MMP) activity, ${ }^{10-12)}$ and recruitment of leukocytes into the retina $^{8)}$ are also involved. These events precede the occurrence of retinal ganglion cell apoptosis, and preventive interventions have been shown to ameliorate NMDA-induced retinal ganglion cell death. Thus, excessive activation of NMDA receptors appears to affect retinal neuronal cell survival by indirect as well as direct mechanisms.

A single intravitreal injection of NMDA into the eye is commonly used in vivo model to induce different forms of retinal damage, such as retinal ganglion cell apoptosis, thinning of the inner retina, and visual dysfunction. ${ }^{13,14)}$ More recently, injury to the retinal microvasculature, including capillary degeneration, has also been demonstrated in the same model. ${ }^{15,16)}$ Pathological changes in retinal circulation could contribute to the progression of retinal diseases, including diabetic retinopathy and glaucoma. ${ }^{17-21)}$ Therefore, the NMDA-induced retinal injury model would be useful for screening novel interventions and approaches for treating such retinal diseases by protecting from neuro/vascular injury.

Nafamostat mesilate (FUT-175, 6-amidino-2-napthyl-4-guanidinobenzoate) was originally developed as a complement inhibitor $^{22}$ and is used for the treatment of pancreatitis and disseminated intravascular coagulation. ${ }^{23,24)}$ Nafamostat mesilate has also been shown to exert broad inhibitory effects against serine proteases, especially tryptase, ${ }^{25)}$ and decrease activities of MMP-9. ${ }^{26,27)}$ The purpose of the present study

The authors declare no conflict of interest. was to determine whether nafamostat mesilate has a neuro/ vascular protective effect in the retina by assessing its effects on the retinal neuronal and capillary degeneration in the rat retina induced by intravitreal injection of NMDA.

\section{MATERIALS AND METHODS}

Animals Male Sprague-Dawley rats weighing 220-240g were maintained in a room at a constant temperature (22士 $\left.2{ }^{\circ} \mathrm{C}\right)$ and at constant humidity $(55 \pm 5 \%)$ under a 12 -h light/ dark cycle, and allowed free access to regular rat chow and tap water.

All animal procedures were performed in accordance with the Association for Research in Vision and Ophthalmology Statement on the Use of Animals in Ophthalmic and Vision Research, and the Regulations the Care and Use of Laboratory Animals in Kitasato University adopted by the Institutional Animal Care and Use Committee for Kitasato University.

Evaluation of the Neuro/Vascular Injury The animals were divided into 2 groups: NMDA+vehicle (saline) $(n=14)$ and NMDA+nafamostat mesilate $(n=15)$. Under general anesthesia with $50 \mathrm{mg} / \mathrm{kg}$ pentobarbital sodium (Nacalai Tesque, Kyoto, Japan), nafamostat mesilate (100 nmol; Sigma-Aldrich, St. Louis, MO, U.S.A.) or vehicle (saline), mixed with $200 \mathrm{nmol}$ of NMDA (Nacalai Tesque) in a total volume of $5 \mu \mathrm{L}$, was injected into the vitreous cavity of one eye. The same volume of vehicle $(5 \mu \mathrm{L})$ was injected into the vitreous cavity of the other eye as a control. In a separate experiment $(n=4)$, the effect of intravitreal injection of nafamostat mesilate $(100 \mathrm{nmol})$ alone on the retina was examined. Damage to the inner retinal layers and retinal blood vessels was assessed $7 \mathrm{~d}$ after the injection.

For assessment of the damage to retinal neurons, the rats were anesthetized with pentobarbital sodium and their eyes were enucleated. The eyes were immersed in a fixative mixture $37.5 \%$ ethanol, $9.3 \%$ formaldehyde, $12.5 \%$ acetic acid, and $3 \%$ glutaraldehyde) for $12 \mathrm{~h}$ at room temperature, as previously reported. ${ }^{28)}$ Fixed retinal tissues were embedded in paraffin, and 5- $\mu \mathrm{m}$ cross-sections were cut through the optic disc of the eye. The sections were stained with hematoxylin 
and eosin. Neuronal damage was assessed by counting the number of cells in the ganglion cell layer (GCL) at a distance of $1000-1250 \mu \mathrm{m}$ from the center of the optic nerve head on both sides and by measuring the thickness of the inner plexiform layer (IPL) in 5 areas approximately $1 \mathrm{~mm}$ adjacent to the optic nerve on both sides. The values were averaged for each eye.

To assess the damage to retinal blood vessels, we performed immunohistochemical staining for endothelial cells and vascular basement membrane, as previously reported. ${ }^{16)}$ The vasculature of each rat (anesthetized with pentobarbital sodium) was perfused with $1 \%$ paraformaldehyde in phosphate-buffered saline (PBS) ( $\mathrm{pH}$ 7.4) from an 18-gauge cannula inserted into the aorta via an incision in the left ventricle for $4 \mathrm{~min}$ at a pressure of $120 \mathrm{mmHg}$. The right atrium was incised to create a route for the fixative solution to exit. After the perfusion, eyes were removed and stored in fixative agent for $24 \mathrm{~h}$ at $4^{\circ} \mathrm{C}$. The retina was separated from the lens, vitreous, and pigment epithelium with 4 radial cuts and then incubated in 5\% normal hamster serum in PBS containing $0.3 \%$ Triton $\mathrm{X}-100$ (PBS $/ 0.3 \%$ Triton $\mathrm{X}-100$ ) for $0.5-1 \mathrm{~h}$ at room temperature. Retinas were incubated for $12-15 \mathrm{~h}$ with primary antibodies diluted in 5\% normal hamster serum in PBS $/ 0.3 \%$ Triton X-100 at room temperature. Retinal endothelial cells and vascular basement membrane were labeled with mouse monoclonal anti-rat endothelial cell antigen (RECA)-1 antibody (1:200; Serotec, Oxford, U.K.) and rabbit polyclonal anti-type IV collagen antibody (1:8000; Cosmo Bio Co., Tokyo, Japan), respectively. After incubation with primary antibodies, the retinas were rinsed with $\mathrm{PBS} / 0.3 \%$ Triton X-100 and incubated for $4 \mathrm{~h}$ at room temperature with fluorescein isothiocyanate (FITC)- or Cy3-labeled, speciesspecific secondary antibodies against anti-RECA antibody (anti-mouse) and anti-type IV collagen antibody (anti-rabbit) (1:400; Jackson ImmunoResearch Laboratories Inc., West Grove, PA, U.S.A.). Retinas were rinsed with PBS/0.3\% Triton $\mathrm{X}-100$ and retinal flat-mounts were prepared with a mounting medium for fluorescence analysis (Vectashield, Vector Laboratories, Burlingame, CA, U.S.A.). Images were collected using a fluorescent microscope system BZ-9000 (Keyence, Osaka, Japan) or a confocal laser scanning microscope LSM 510 Meta (Zeiss, Oberkochen, Germany). Five images of the regions of the mid-peripheral retina (fields at $10 \times$, corresponding to a retinal area of $1.58 \mathrm{~mm}^{2}$ each) were obtained from each retinal flat-mount to count the empty sleeves of basement membranes.

Measurement of Tryptase-Like Protease Activity The tryptase-like protease activity in retinas was determined $1 \mathrm{~d}$ after intravitreal injection of NMDA $(200 \mathrm{nmol}, n=7)$, nafamostat mesilate $(100 \mathrm{nmol}, n=5)$, or combination of NMDA plus nafamostat mesilate $(n=5)$. This time point was selected on the basis of our preliminary time-course study, indicating that the tryptase-like protease activity was increased in the retina $1 \mathrm{~d}$ after intravitreal injection of NMDA, but the activity gradually declined (unpublished data). By using the technique described above, $200 \mathrm{nmol}$ of NMDA, $100 \mathrm{nmol}$ of nafamostat mesilate, or the combination in a total volume of $5 \mu \mathrm{L}$ was injected into the vitreous cavity of one eye. The contralateral eye was used as a control, and the same volume of vehicle (saline) was injected into the vitreous cavity of the contralateral eye. Tryptase-like protease activity in the retina was determined according to the method described by Wolters
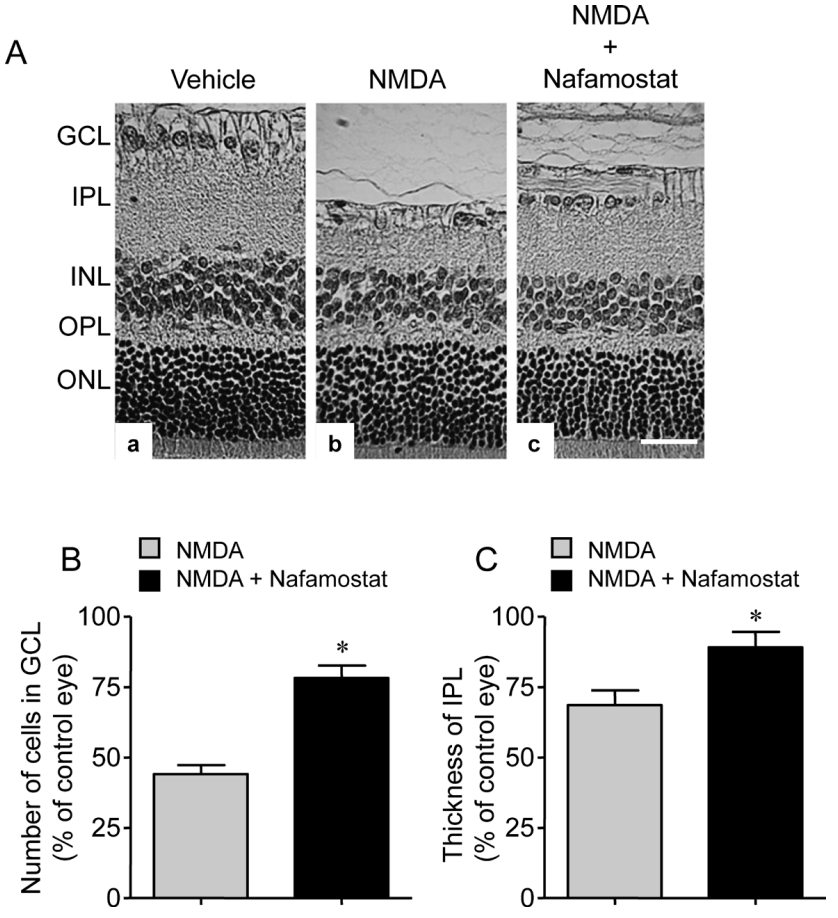

Fig. 1. Effects of Nafamostat Mesilate on Retinal Neuronal Damage in NMDA-Treated Retinas

(A) Representative photomicrographs of retinal cross-sections $7 \mathrm{~d}$ after an intravitreal injection of vehicle (a), NMDA+vehicle (b), and NMDA+nafamostat mesilate (c). (B, C) Evaluation of retinal damage by counting the number of cells in the retinal ganglion cell layer (GCL) (B) and by measuring the thickness of the inner plexiform layer (IPL) (C). INL, inner nuclear layer; OPL, outer plexiform layer; ONL, outer nuclear layer. Each column with a vertical bar represents the mean + S.E. of the results for $8-9$ animals. $* p<0.05 v s$. NMDA. Scale bar: $40 \mu \mathrm{m}$

et $a l .{ }^{29)}$ In brief, each retina was homogenized in $10 \mathrm{~mm}$ bis(2hydroxyethyl)iminotris(hydroxymethyl)methane (bis-Tris, $\mathrm{pH}$ 6.1) containing $2 \mathrm{M} \mathrm{NaCl}$. The solution was centrifuged at $14000 \times \boldsymbol{g}$ for $10 \mathrm{~min}$ at $4^{\circ} \mathrm{C}$. Eighty microliters of the supernatant $(1.2 \mathrm{mg}$ protein $/ \mathrm{mL})$ was added to $160 \mu \mathrm{L}$ of reaction solution $(300 \mu \mathrm{g} / \mathrm{mL} N$ - $p$-Tosyl-Gly-Pro-Arg- $p$-nitroanilide, $60 \mathrm{~mm}$ Tris [pH 7.8], 0.4\% dimethyl sulfoxide and $30 \mu \mathrm{g} / \mathrm{mL}$ heparin) at $37^{\circ} \mathrm{C}$. Free nitroaniline released was measured using a colorimeter at $410 \mathrm{~nm}$. In the presence of $100 \mu \mathrm{M}$ nafamostat mesilate in the reaction solution, no change in absorbance was observed. The tryptase-like protease activity was expressed as the change in absorbance $/ \mathrm{h} / \mathrm{g}$ protein.

Statistical Analyses All values are presented as the mean \pm S.E. Unpaired $t$-test and Tukey's test were used for the comparisons between 2 groups and among more than 2 groups, respectively (GraphPad, San Diego, CA, U.S.A.). A $p$ value of less than 0.05 was considered statistically significant.

\section{RESULTS}

Figure 1A shows representative microscopic photographs of the rat retinal sections $7 \mathrm{~d}$ after intravitreal injection of vehicle, NMDA, or NMDA+nafamostat mesilate. The cell number in the GCL and the thickness of the IPL were reduced $7 \mathrm{~d}$ after treatment with NMDA, compared with those in the vehicle-treated retina (Figs. $1 \mathrm{~A}-\mathrm{C}$ ). On the other hand, visible changes in the inner nuclear layer (INL), the outer plexiform layer (OPL), and the outer nuclear layer (ONL) were not 

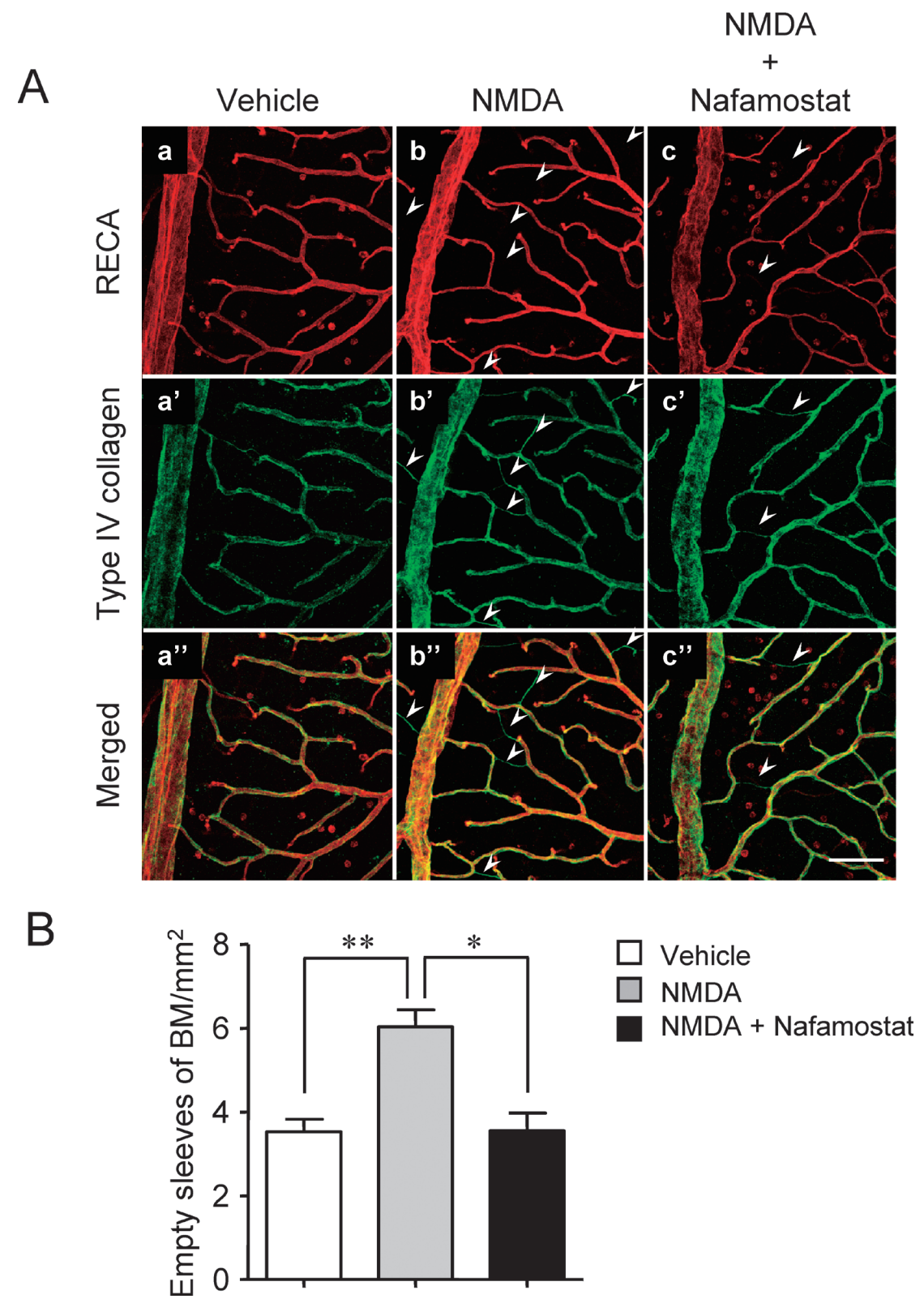

Fig. 2. Effects of Nafamostat Mesilate on Retinal Vascular Damage in the NMDA-Treated Retinas

(A) Representative photomicrographs of retinal flat-mounts showing RECA-positive endothelial cells and type IV collagen-positive basement membrane $7 \mathrm{~d}$ after intravitreal injection of vehicle $\left(a, a^{\prime}, a^{\prime \prime}\right)$, NMDA+vehicle $\left(b, b^{\prime}, b^{\prime \prime}\right)$, and NMDA+ nafamostat mesilate $\left(c, c^{\prime}, c^{\prime \prime}\right)$. Arrowheads indicate empty basement membrane sleeves that were left as remnants of the vessels. (B) The number of empty sleeves of basement membrane (BM) in each group is shown. Each column with a vertical bar represents the mean + S.E. of the results from $6-12$ animals. $* * p<0.001, * p<0.01 v s$. vehicle. Scale bar: $100 \mu \mathrm{m}$.

observed (Fig. 1A). When nafamostat mesilate was injected with NMDA simultaneously, cell loss in the GCL and IPL thinning were significantly attenuated (Figs. 1A-C). Nafamostat mesilate alone had no significant effect on retinas (cell number in the GCL: control, $84 \pm 5.0$ cells $/ \mathrm{mm}$ vs. nafamostat mesilate, $76 \pm 8$ cells $/ \mathrm{mm} ; n=4$; thickness of the IPL: control, $37.5 \pm 1.4 \mu \mathrm{m} v s$. nafamostat mesilate, $36.7 \pm 1.8 \mu \mathrm{m}, n=4)$.

Figure 2 shows representative photomicrographs of retinal flat-mounts labeled with antibodies for endothelial cells (RECA) and vascular basement membrane (type IV collagen). The immunoreactivity of type IV collagen was almost completely colocalized with RECA staining of blood vessels in control retina (Figs. 2Aa, $\mathrm{Aa}^{\prime}, \mathrm{Aa}^{\prime \prime}$ ), but the number of empty sleeves of vascular basement membrane increased $7 \mathrm{~d}$ after NMDA treatment (Figs. $2 \mathrm{Ab}, \mathrm{Ab}^{\prime}, \mathrm{Ab}^{\prime \prime}$ ). The increase was markedly diminished by treatment with nafamostat mesilate (Figs. 2 Ac, Ac', Ac", B).

Figure 3 shows effects of NMDA, the combination of NMDA plus nafamostat mesilate, and nafamostat mesilate alone on tryptase-like protease activity in retinas. The activity in NMDA-treated retinas was significantly higher than that in control retinas (Fig. 3A). However, surprisingly, the simultaneous administration of NMDA and nafamostat mesilate markedly increased the tryptase-like protease activity (Fig. 3B) and nafamostat mesilate alone enhanced the activity (Fig. 3C).

\section{DISCUSSION}

Glutamate levels are elevated in the eyes of patients with diabetic retinopathy ${ }^{2,3)}$ or some types of glaucoma.' ${ }^{1)}$ Evidence 

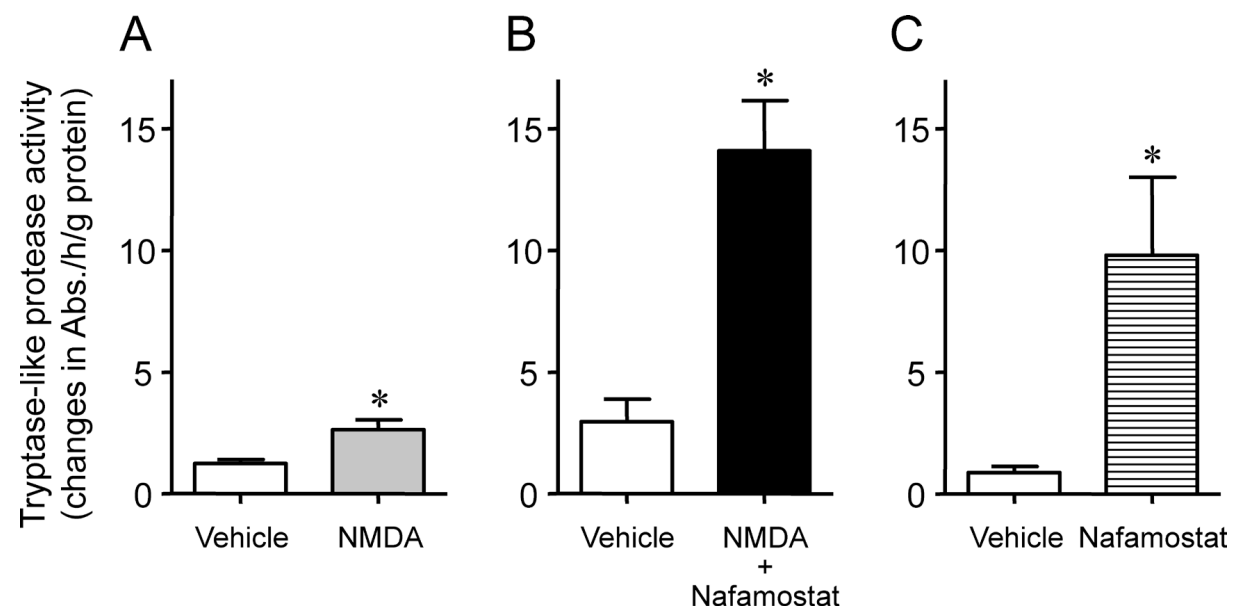

Fig. 3. Effects of NMDA, the Combination of NMDA Plus Nafamostat Mesilate, and Nafamostat Mesilate Alone on Tryptase-Like Protease Activity in Retinas

One day after an intravitreal injection of NMDA plus nafamostat mesilate, nafamostat mesilate alone or vehicle (saline), protease activity was assessed by measuring the rate of hydrolysis of the chromogenic substrate $N$ - $p$-Tosyl-Gly-Pro-Arg- $p$-nitroanilide at $410 \mathrm{~nm}$. Each column with a vertical bar represents the mean $+\mathrm{S}$.E. of the results for 5-7 animals. ${ }^{*} p<0.05$ vs. vehicle.

indicates that pathological changes in retinal circulation could contribute to the progression of retinal diseases, including diabetic retinopathy and glaucoma. ${ }^{16-20)}$ Therefore, neuro/vascular protective interventions are a potential strategy for preventing progression of such retinal diseases. The present study demonstrates that nafamostat mesilate, a serine protease inhibitor, significantly prevents the degeneration of both the neuronal and vascular components in NMDA-treated retinas.

Nafamostat mesilate is recognized as a potent inhibitor of serine proteases and shows more than 100 -fold higher affinity for human tryptase than for other proteases such as thrombin and trypsin. ${ }^{25}$ Tryptase is one of the major proteins stored in mast cells, which are a key cellular component of the inflammatory response. When activated, the cells secrete tryptase as well as numerous proinflammatory mediators, including histamine, arachidonic acid derivatives, and some serine proteases. Consequently, at sites of tissue injury, mast cellderived tryptases are present in relatively high concentrations. Because a potentially deleterious role of mast cells in the very early phase of acute cerebral ischemia and hemorrhage has been suggested ${ }^{30}$ ) the beneficial effects observed in this study might be attributed to tryptase inhibition. To test this possibility, we determined changes in tryptase-like protease activity induced by NMDA and found that the activity was increased in the retina $1 \mathrm{~d}$ after intravitreal injection of NMDA. However, the simultaneous administration of NMDA and nafamostat mesilate increased the tryptase-like protease activity more than NMDA alone. Furthermore, the activity was enhanced by treatment with nafamostat mesilate alone. The exact mechanisms of these phenomena are unclear, but enzymes that are inhibited by nafamostat mesilate may regulate the activity and/or expression of other serine proteases that can degrade the substrate $N$ - $p$-Tosyl-Gly-Pro-Arg- $p$-nitroanilide in rat retina. Multiple enzymes may interact with each other. Nafamostat mesilate is capable of inhibiting other serine proteases, including trypsin and some proteases that are involved in the coagulation process. ${ }^{31-33)}$ In addition, nafamostat mesilate can decrease the activity levels of MMPs. ${ }^{26,27)}$

Nafamostat mesilate per se exhibited no significant morphological changes in retina. Therefore, the observed changes in enzyme activity may not be associated with the retinal injury. However, local changes in enzyme activity occurring within GCL and IPL might be masked because whole retina was used for measuring the enzyme activity in the present study. Further studies are needed to clarify the mechanisms underlying the protective effects of nafamostat mesilate against retinal damage.

The retinal vascular damage was almost completely prevented by nafamostat mesilate, whereas retinal ganglion cell loss was significantly but incompletely attenuated. The data imply that nafamostat mesilate might exert a protective effect against vascular damage. However, there could be an alternative explanation. We found that significant neuronal cell loss was observed without an increase in capillary degeneration $2 \mathrm{~d}$ after NMDA treatment (data not shown). Therefore, there seems to be a certain threshold level of retinal neural degeneration in terms of the degree and duration before the onset of retinal vascular degeneration. Decreasing neuronal cell death with nafamostat mesilate may be sufficient to preclude the level of retinal neural degeneration necessary to induce retinal vascular degeneration. To address this issue, future studies should aim to determine whether nafamostat mesilate injected at 1 or $2 \mathrm{~d}$ after NMDA treatment provides any protective effects.

In conclusion, we found that nafamostat mesilate affords protection from neuronal and vascular injury in NMDA-treated retinas. The precise mechanisms underlying the beneficial effects remain unclear; however, our results indicate that nafamostat mesilate may be considered as a candidate for neuro/ vascular protective interventions in retinal diseases associated with glutamate-induced excitotoxicity.

Acknowledgments This study was supported by a Grantin-Aid for Scientific Research on Innovative Areas (No. 23122517, T.N.) and Grants-in-Aid for Scientific Research (C) from the Ministry of Education, Culture, Sports, Science and Technology of Japan (No. 20590090 and No. 23590112, T.N.). 


\section{REFERENCES}

1) Dreyer EB, Zurakowski D, Schumer RA, Podos SM, Lipton SA. Elevated glutamate levels in the vitreous body of humans and monkeys with glaucoma. Arch. Ophthalmol., 114, 299-305 (1996).

2) Ambati J, Chalam KV, Chawla DK, D'Angio CT, Guillet EG, Rose SJ, Vanderlinde RE, Ambati BK. Elevated gamma-aminobutyric acid, glutamate, and vascular endothelial growth factor levels in the vitreous of patients with proliferative diabetic retinopathy. Arch. Ophthalmol., 115, 1161-1166 (1997).

3) Pulido JE, Pulido JS, Erie JC, Arroyo J, Bertram K, Lu MJ, Shippy SA. A role for excitatory amino acids in diabetic eye disease. Exp. Diabetes Res., 2007, 36150 (2007).

4) Morizane C, Adachi K, Furutani I, Fujita Y, Akaike A, Kashii S, Honda YN. N(omega)-Nitro-L-arginine methyl ester protects retinal neurons against $N$-methyl-D-aspartate-induced neurotoxicity in vivo. Eur. J. Pharmacol., 328, 45-49 (1997).

5) Vorwerk CK, Hyman BT, Miller JW, Husain D, Zurakowski D, Huang PL, Fishman MC, Dreyer EB. The role of neuronal and endothelial nitric oxide synthase in retinal excitotoxicity. Invest. Ophthalmol. Vis. Sci., 38, 2038-2044 (1997).

6) Chiu K, Lam TT, Ying Li WW, Caprioli J, Kwong Kwong JM. Calpain and $N$-methyl-D-aspartate (NMDA)-induced excitotoxicity in rat retinas. Brain Res., 1046, 207-215 (2005).

7) Shimazawa $M$, Suemori $S$, Inokuchi $Y$, Matsunaga $N$, Nakajima Y, Oka T, Yamamoto T, Hara H. A novel calpain inhibitor, ((1S)1-((((1S)-1-benzyl-3-cyclopropylamino-2,3-di-oxopropyl)amino)carbonyl)-3-methylbutyl)carbamic acid 5-methoxy-3-oxapentyl ester (SNJ-1945), reduces murine retinal cell death in vitro and in vivo. $J$. Pharmacol. Exp. Ther., 332, 380-387 (2010).

8) Nakazawa T, Takahashi H, Nishijima K, Shimura M, Fuse N, Tamai M, Hafezi-Moghadam A, Nishida K. Pitavastatin prevents NMDAinduced retinal ganglion cell death by suppressing leukocyte recruitment. J. Neurochem., 100, 1018-1031 (2007).

9) Al-Gayyar MM, Abdelsaid MA, Matragoon S, Pillai BA, ElRemessy AB. Thioredoxin interacting protein is a novel mediator of retinal inflammation and neurotoxicity. Br. J. Pharmacol., 164, 170-180 (2011).

10) Zhang $X$, Sakamoto $T$, Hata $Y$, Kubota T, Hisatomi T, Murata T, Ishibashi T, Inomata $H$. Expression of matrix metalloproteinases and their inhibitors in experimental retinal ischemia-reperfusion injury in rats. Exp. Eye Res., 74, 577-584 (2002).

11) Manabe S, Gu Z, Lipton SA. Activation of matrix metalloproteinase-9 via neuronal nitric oxide synthase contributes to NMDAinduced retinal ganglion cell death. Invest. Ophthalmol. Vis. Sci., 46, 4747-4753 (2005).

12) Mathalone N, Lahat N, Rahat MA, Bahar-Shany K, Oron Y, Geyer $\mathrm{O}$. The involvement of matrix metalloproteinases 2 and 9 in rat retinal ischemia. Graefes Arch. Clin. Exp. Ophthalmol., 245, 725-732 (2007).

13) Lam TT, Abler AS, Kwong JM, Tso MO. N-Methyl-D-aspartate (NMDA) - induced apoptosis in rat retina. Invest. Ophthalmol. Vis. Sci., 40, 2391-2397 (1999).

14) Manabe S, Lipton SA. Divergent NMDA signals leading to proapoptotic and antiapoptotic pathways in the rat retina. Invest. Ophthalmol. Vis. Sci., 44, 385-392 (2003).

15) Al-Gayyar MM, Abdelsaid MA, Matragoon S, Pillai BA, ElRemessy AB. Neurovascular protective effect of FeTPPs in $\mathrm{N}$ methyl-D-aspartate model: similarities to diabetes. Am. J. Pathol., 177, 1187-1197 (2010).

16) Ueda K, Nakahara $T$, Hoshino M, Mori A, Sakamoto K, Ishii
K. Retinal blood vessels are damaged in a rat model of NMDAinduced retinal degeneration. Neurosci. Lett., 485, 55-59 (2010).

17) Ghirlanda G, Di Leo MA, Caputo S, Cercone S, Greco AV. From functional to microvascular abnormalities in early diabetic retinopathy. Diabetes Metab. Rev., 13, 15-35 (1997).

18) Schmetterer L, Wolzt M. Ocular blood flow and associated functional deviations in diabetic retinopathy. Diabetologia, 42, 387-405 (1999).

19) De La Cruz JP, González-Correa JA, Guerrero A, de la Cuesta FS. Pharmacological approach to diabetic retinopathy. Diabetes Metab. Res. Rev., 20, 91-113 (2004).

20) Flammer J, Orgül S, Costa VP, Orzalesi N, Krieglstein GK, Serra LM, Renard JP, Stefánsson E. The impact of ocular blood flow in glaucoma. Prog. Retin. Eye Res., 21, 359-393 (2002).

21) Grieshaber MC, Flammer J. Blood flow in glaucoma. Curr. Opin. Ophthalmol., 16, 79-83 (2005).

22) Fujii S, Hitomi Y. New synthetic inhibitors of C1r, C1 esterase, thrombin, plasmin, kallikrein and trypsin. Biochim. Biophys. Acta, 661, 342-345 (1981).

23) Yoshikawa T, Murakami M, Furukawa Y, Kato H, Takemura S, Kondo M. Effects of FUT-175, a new synthetic protease inhibitor on endotoxin-induced disseminated intravascular coagulation in rats. Haemostasis, 13, 374-378 (1983).

24) Iwaki M, Ino Y, Motoyoshi A, Ozeki M, Sato T, Kurumi M, Aoyama T. Pharmacological studies of FUT-175, nafamostat mesilate. V. Effects on the pancreatic enzymes and experimental acute pancreatitis in rats. Jpn. J. Pharmacol., 41, 155-162 (1986).

25) Mori S, Itoh Y, Shinohata R, Sendo T, Oishi R, Nishibori M. Nafamostat mesilate is an extremely potent inhibitor of human tryptase. J. Pharmacol. Sci., 92, 420-423 (2003).

26) Yamashita $Y$, Ishiguro $Y$, Sano D, Kimura M, Fujita K, Yoshida T, Horiuchi C, Taguchi T, Matsuda H, Mikami Y, Tsukuda M. Antitumor effects of nafamostat mesilate on head and neck squamous cell carcinoma. Auris Nasus Larynx, 34, 487-491 (2007).

27) Fujiwara Y, Furukawa K, Haruki K, Shimada Y, Iida T, Shiba H, Uwagawa T, Ohashi T, Yanaga K. Nafamostat mesilate can prevent adhesion, invasion and peritoneal dissemination of pancreatic cancer thorough nuclear factor kappa-B inhibition. J. Hepatobiliary Pancreat. Sci., 18, 731-739 (2011).

28) Mori A, Ishii T, Kuroki T, Shigeta N, Sakamoto K, Nakahara T, Ishii K. The prostanoid EP(2) receptor agonist ONO-AE1-259-01 protects against glutamate-induced neurotoxicity in rat retina. Eur. J. Pharmacol., 616, 64-67 (2009).

29) Wolters PJ, Pham CT, Muilenburg DJ, Ley TJ, Caughey GH. Dipeptidyl peptidase I is essential for activation of mast cell chymases, but not tryptases, in mice. J. Biol. Chem., 276, 18551-18556 (2001).

30) Lindsberg PJ, Strbian D, Karjalainen-Lindsberg ML. Mast cells as early responders in the regulation of acute blood-brain barrier changes after cerebral ischemia and hemorrhage. J. Cereb. Blood Flow Metab., 30, 689-702 (2010).

31) Hitomi Y, Ikari N, Fujii S. Inhibitory effect of a new synthetic protease inhibitor (FUT-175) on the coagulation system. Haemostasis, 15, 164-168 (1985).

32) Aoyama T, Ino Y, Ozeki M, Oda M, Sato T, Koshiyama Y, Suzuki S, Fujita M. Pharmacological studies of FUT-175, nafamstat mesilate. I. Inhibition of protease activity in in vitro and in vivo experiments. Jpn. J. Pharmacol., 35, 203-227 (1984).

33) Uchiba M, Okajima K, Abe H, Okabe H, Takatsuki K. Effect of nafamostat mesilate, a synthetic protease inhibitor, on tissue factorfactor VIIa complex activity. Thromb. Res., 74, 155-161 (1994). 